\title{
FITOTOXICIDADE CAUSADA A CULTURA DA SOJA PELA APLICAÇÃO FOLIAR DE LACTOFEN COM Co E Mo
}

\author{
Lília Sichmann Heiffig-del Aguila ${ }^{1}$, Gil Miguel de Sousa Câmara ${ }^{1}$, Juan Saavedra del Aguila ${ }^{2}$, Helder \\ Roberto Dota Janoselli², José Felipe Gonzaga Sabadin², Sônia Maria De Stefano Piedade², Cláudio \\ Roberto Segatelli ${ }^{2}$ \\ ${ }^{1}$ Embrapa Clima Temperado, Cx. Postal 403, cep. 96010-971, Pelotas-RS, \\ ${ }^{2}$ USP/ESALQ, Av. Pádua Dias, 11 - Cx. Postal 9, cep. 13418-900, Piracicaba-SP
}

\section{RESUMO}

Com o objetivo de avaliar o pH das soluções do herbicida pós-emergente Lactofen em mistura com os micronutrientes Co e Mo e a fitotoxicidade causada a cultura da soja, cv. Conquista, pela aplicação foliar destas no estádio fenológico $\mathrm{V}_{5}$, o presente trabalho de pesquisa foi conduzido na Escola Superior de Agricultura "Luiz de Queiroz" (USP/ESALQ), em Piracicaba-SP, durante os anos agrícolas 2003/04 e 2005/06 em solo LATOSSOLO AMARELO Distrófico típico. Delineado experimentalmente sob blocos ao acaso com quatro repetições, os onze tratamentos constaram de diferentes formas de aplicação e interações entre os micronutrientes Co e Mo (CoMo) e o herbicida pós-emergente Lactofen: T1: controle; T2: tratamento de sementes com CoMo; T3: tratamento de sementes com CoMo + aplicação de herbicida em $\mathrm{V}_{5}$; T4: aplicação foliar de CoMo em $\mathrm{V}_{5}$; T5 = aplicação foliar de CoMo + herbicida em $\mathrm{V}_{5}$; T6: aplicação de herbicida em $\mathrm{V}_{5}+$ foliar de CoMo 3 a 5 dias após; T7: aplicação foliar de CoMo em $\mathrm{V}_{5}+$ aplicação de herbicida 3 a 5 dias após; T8: aplicação foliar de Co em $\mathrm{V}_{5}$; T9: aplicação foliar de $\mathrm{Co}+$ herbicida em $\mathrm{V}_{5}$; T10: aplicação foliar de Mo em $\mathrm{V}_{5}$; T11: aplicação foliar de $\mathrm{Mo}+$ herbicida em $\mathrm{V}_{5}$. Foram avaliados: $\mathrm{pH}$ das soluções de Lactofen e de micronutrientes e avaliação da fitotoxicidade causada pelo herbicida Lactofen. Conclui-se que a aplicação foliar do herbicida Lactofen no estádio fenológico $\mathrm{V}_{5}$ da cultura da soja causa fitotoxicidade às folhas, em grau variável de leve a médio.

Palavras-chave: Glycine max; cobalto; molibdênio; pH

\section{PHYTOTOXICITY ON SOYBEAN DUE TO FOLIAR APPLICATION OF LACTOFEN MIXED WITH COBALT AND MOLYBDENUM}

\section{ABSTRACT}

The purpose of this work was to evaluate how foliar applications of the post-emergence herbicide Lactofen mixed with the micronutrients $\mathrm{Co}$ and $\mathrm{Mo}$ at $\mathrm{V}_{5}$ phenological stage influence the $\mathrm{pH}$ and the phytotoxicity of soybean, cv Conquista. The study was conducted in the Escola Superior de Agricultura "Luiz de Queiroz" (USP/ESALQ), Piracicaba-SP, in an Oxisol, during the crop years 2003/04 and 2005/06. The eleven treatments tested involved different application procedures and interactions between the micronutrients Co and Mo (CoMo) and the post-emergence herbicide Lactofen in a randomized block design, with four replicates. Treatments were T1: control; T2: seeds treated with CoMo; T3: seeds treated with CoMo + herbicide application at $\mathrm{V}_{5}$ stage; T4: foliar-applied CoMo at $\mathrm{V}_{5}$ stage; T5: foliarapplied $\mathrm{CoMo}+$ herbicide application at $\mathrm{V}_{5}$ stage; T6: herbicide application at $\mathrm{V}_{5}$ stage + foliar-applied CoMo 3 to 5 days after herbicide application; T7: foliar-applied CoMo at $V_{5}$ 
stage + herbicide application 3 to 5 days after micronutrients application; T8: foliar-applied Co at $\mathrm{V}_{5}$ stage; T9: foliar-applied $\mathrm{Co}+$ herbicide application at $\mathrm{V}_{5}$ stage; T10: foliar-applied Mo at $\mathrm{V}_{5}$ stage; T11: foliar-applied $\mathrm{Mo}+$ herbicide application at $\mathrm{V}_{5}$ stage. The parameters evaluated were: $\mathrm{pH}$ of Lactofen and micronutrient solutions and the phytotoxicity caused by Lactofen. It was concluded that the foliar application of Lactofen to soybean at $\mathrm{V}_{5}$ phenological stage leads to leaf phytotoxicity at mild to moderate levels.

Key words: Glycine max; cobalt; molybdenum; $\mathrm{pH}$

\section{INTRODUÇÃO}

A soja [Glycine max (L.) Merrill], constitui-se em um dos principais cultivos da agricultura mundial e brasileira, devido ao seu potencial produtivo e a sua composição química e valor nutritivo, que lhe confere multiplicidade de aplicações na alimentação humana e animal, com relevante papel sócioeconômico, além de se constituir em matéria-prima indispensável, para impulsionar diversos complexos agroindustriais.

Na cultura da soja é freqüente o uso de herbicidas seletivos de ação pós-emergente como ferramenta do controle químico das plantas daninhas, tanto para o controle das de folhas estreitas, como para o controle específico das de folhas largas.

Segundo Veline et al. (1992), seletividade é a capacidade de um determinado herbicida eliminar plantas daninhas que se encontram em uma determinada cultura sem reduzir a produtividade e a qualidade do produto obtido, não podendo a seletividade ser determinada apenas pela verificação ou não de sintomas de fitotoxicidade, pois são conhecidos exemplos de herbicidas que podem reduzir a produtividade das culturas sem produzir efeitos visualmente detectáveis, bem como, existem herbicidas que provocam injúrias bastante acentuadas, mas que permitem às mesmas, manifestar plenamente seus potenciais produtivos.
Normalmente, os latifolicidas pósemergentes são aplicados entre os estádios fenológicos $V_{3}$ e $V_{5}$ da soja. Conforme a natureza da molécula aplicada, da sensibilidade da cultivar, da dose utilizada, da tecnologia de aplicação adotada e das condições ambientais por ocasião da pulverização, poderá ocorrer maior ou menor grau de injúria às plantas de soja.

Warren \& Hess (1990) explicam que os sintomas de fitotoxicidade caracterizam-se por necrose foliar iniciada quatro a seis horas após a aplicação em pós-emergência e sob presença de luz. Os primeiros sintomas têm aparência de embebição de água (manchas verde escuras nas folhas), seguidas por necrose dos tecidos. Essa aparência do tecido encharcado evidencia a ocorrência de dano na membrana celular com perda das substâncias celulares para os espaços intercelulares. Os sintomas de fitotoxidez aparecem nas folhas já desenvolvidas no momento da aplicação, e podem manifestarse na forma de cloroses, bronzeamentos, pontos ou tecidos necróticos, enrugamento dos trifólios (Gazziero \& Neumaier, 1985; Taylor, 1985; Kapusta et al., 1986; Wichert \& Talbert, 1993) ou enrugamento da borda das folhas novas (Taylor, 1985). Estes sintomas tendem a desaparecer com o surgimento das folhas novas, ocorrendo rápida recuperação das plantas afetadas (Almeida \& Rodrigues, 1988; Kapusta et al., 1986). 
O tratamento das sementes de soja com formulações fluidas contendo os micronutrientes cobalto $(\mathrm{Co})$ e molibdênio (Mo) também é de uso frequiente na cultura da soja.

Em soja, planta com elevado teor de proteínas, a necessidade de nitrogênio é atendida principalmente pela fixação biológica, através da associação com a bactéria bradirrizóbio. A deficiência de Mo traduz-se em deficiência de N. O molibdênio é elemento essencial nos processos de obtenção de $\mathrm{N}$ pela soja. O Mo catalisa a redução de nitrogênio, na forma de nitrato, no complexo enzimático nitrato redutase, e a redução do nitrogênio, na forma gasosa $\left(\mathrm{N}_{2}\right)$, na enzima nitrogenase (Marschner, 1990). Com as nitrato redutases, produzidas pelas plantas, o nitrato absorvido é transformado em amônio, e assim o nitrogênio é assimilado nas vias biossintéticas, indo fazer parte dos aminoácidos e proteínas.

Segundo Malavolta (1980), também o cobalto é essencial para a fixação do $\mathrm{N}_{2} \mathrm{em}$ sistemas simbióticos, como é o caso da soja e o bradirrizóbio. O Co constitui o grupo prostéstico associado com um nucleotídeo na vitamina $\mathrm{B}_{12}$, que funciona como coenzima. Nos nódulos, os rizóbios necessitam de Co para sintetizar a vitamina $\mathrm{B}_{12}$ como a coenzima cobamida.

Devido à elevada concentração salina sobre as sementes, resultando em aumento de mortalidade das bactérias inoculadas; muitos produtores retiraram os micronutrientes do tratamento das sementes, aplicando-os via foliar entre os estádios $\mathrm{V}_{3} \mathrm{e}$ $\mathrm{V}_{5}$ da soja. Na prática agrícola, por questões de ordem econômica, surgiu o uso da mistura de tanque em que, no mesmo volume de água adicionam-se, simultaneamente, herbicida pós-emergente e solução contendo Co e Mo.

Embora de uso comum, é pouco conhecido o efeito da interação herbicida pós-emergente e micronutrientes Co e Mo provenientes da mesma solução pulverizada. Para alguns produtores e técnicos, a fitotoxicidade do herbicida na soja diminui; para outros, não há nenhum tipo de interação. A revisão bibliográfica sobre o assunto pouco informa.

Os fatos expostos motivaram a apresentação deste trabalho, cujo principal objetivo foi avaliar o $\mathrm{pH}$ das soluções do herbicida pós-emergente Lactofen em mistura com os micronutrientes Co e Mo e a fitotoxicidade causada a cultura da soja pela aplicação foliar destas no estádio fenológico $\mathrm{V}_{5}$.

\section{MATERIAL E MÉTODOS}

A pesquisa foi realizada em condições de campo na Estação Experimental de Anhembi, pertencente à Escola Superior de Agricultura "Luiz de Queiroz" e localizada no município de Piracicaba - SP, a $22^{\circ} 45^{\prime}$ e $22^{\circ} 50^{\prime}$ de Latitude Sul, $48^{\circ} 00^{\prime}$ e $45^{\circ} 05^{\prime}$ de Longitude Oeste e $530 \mathrm{~m}$ de altitude média. Tem o solo classificado como LATOSSOLO AMARELO Distrófico típico, profundo, contendo $200 \mathrm{~g} \mathrm{~kg}^{-1}$ de argila, $80 \mathrm{~g} \mathrm{~kg}^{-1}$ de silte e $720 \mathrm{~g} \mathrm{~kg}^{-1}$ de areia. $\mathrm{O}$ experimento foi conduzido durante os anos agrícolas 2003/2004 e 2005/06, com semeadura, respectivamente em 15 de dezembro de 2003 e 9 de dezembro de 2005, e colheita, respectivamente em 23 de abril de 2004 e 25 de abril de 2006.

A recomendação de adubação de base da cultura de soja, constituída de fósforo e potássio, foi fundamentada na fertilidade do solo, revelada pelas análises químicas, e na produtividade do cultivar estimada para $3.000 \mathrm{~kg} \mathrm{ha}^{-1}$. O nitrogênio foi fornecido para a soja pelo sistema de fixação biológica, a partir da inoculação das sementes com inoculante líquido. 
Foi utilizada a cultivar MG/BR-46 (Conquista), atualmente recomendada para as regiões produtoras de soja do Estado de São Paulo.

O experimento foi conduzido, em blocos ao acaso, constando de 11 tratamentos com quatro repetições. Os tratamentos, correspondentes a diferentes formas de aplicação e interações entre os micronutrientes Co e Mo e o herbicida pósemergente Lactofen foram: T1: Controle (ausência de Co e Mo e de aplicação em pósemergência de herbicida - Lactofen); T2: Co e Mo na semente sem aplicação em pósemergência de herbicida (Lactofen); T3: Co e Mo na semente com aplicação em pósemergência de herbicida (Lactofen) no estádio fenológico $\mathrm{V}_{5}$; T4: Co e Mo foliar no estádio fenológico $\mathrm{V}_{5}$, sem aplicação em pós-emergência de herbicida (Lactofen); T5: Co e Mo foliar + aplicação em pósemergência de herbicida (Lactofen) no estádio fenológico $\mathrm{V}_{5}$; T6: Aplicação em pós-emergência de herbicida (Lactofen) no estádio fenológico $\mathrm{V}_{5}$ e Co + Mo foliar 3-5 dias após; T7: Co + Mo foliar no estádio fenológico $V_{5}$ e aplicação em pósemergência de herbicida (Lactofen) 3-5 dias após; T8: Cobalto (Co) foliar no estádio fenológico $\mathrm{V}_{5}$, sem aplicação em pósemergência de herbicida (Lactofen); T9: Co foliar + aplicação em pós-emergência de herbicida (Lactofen) no estádio fenológico $\mathrm{V}_{5}$; T10: Molibdênio (Mo) foliar no estádio fenológico $\mathrm{V}_{5}$, sem aplicação em pósemergência de herbicida (Lactofen); T11: Mo foliar + aplicação em pós-emergência de herbicida (Lactofen) no estádio fenológico $\mathrm{V}_{5}$.

O espaçamento adotado foi de $0,50 \mathrm{~m}$ entre fileiras, com densidade de 18 plantas por metro, totalizando 360.000 plantas $\mathrm{ha}^{-1}$. Para se obter a população projetada, foi feita contagem do estande inicial. As plantas em excesso foram desbastadas manualmente. Cada parcela constituída por oito linhas teve a largura de 4,0 m e o comprimento de 6,0 $\mathrm{m}$, com área equivalente a $24 \mathrm{~m}^{2}$. Entre cada parcela foi deixado o espaço de $1,0 \mathrm{~m}$ (livre de plantas), correspondente à bordadura.

A profundidade de semeadura foi de aproximadamente $0,05 \mathrm{~m}$. As sementes foram previamente tratadas com fungicida $\mathrm{e}$ inoculadas com estirpes de Bradyrhizobium japonicum. $\mathrm{O}$ fungicida utilizado no tratamento das sementes de soja foi o thiran + thiabendazole, na dose recomendada de 70 $+17 \mathrm{~g}$ de i.a. por $100 \mathrm{~kg}$ de sementes, respectivamente. Como a área experimental possui histórico de soja inoculada, as sementes receberam inoculante líquido na dose equivalente a 600.000 células por semente.

As soluções de Co, Mo e Co + Mo foram formuladas em laboratório. Para a obtenção de $500 \mathrm{~mL}$ de uma solução de Co+Mo, contendo $15 \%$ de Mo e 1,5\% de Co, foram utilizados 378,283 $\mathrm{g}$ de $\mathrm{Na}_{2} \mathrm{MoO}_{4} \cdot 2 \mathrm{H}_{2} \mathrm{O}$ (Molibdato de Sódio), $71,551 \mathrm{~g}$ de $\mathrm{CoSO}_{4} .7 \mathrm{H}_{2} \mathrm{O}$ (Sulfato de Cobalto), 94,394 g de EDTA e 89,0 mL de $\mathrm{NaOH}(1 \mathrm{~N})$. Para a obtenção das soluções individuais de Mo (15\%) e de Co $(1,5 \%)$ foram utilizados os mesmos produtos químicos, mantendo-se as quantidades, entretanto, somente sendo formulados com o produto a que correspondia a solução. Nos tratamentos correspondentes a aplicação de Co e Mo nas sementes, e, também via foliar, estes o foram na dosagem de $150 \mathrm{~mL} \mathrm{ha}^{-1}$.

Finalizando a instalação das parcelas, os experimentos receberam em área total, aplicação de mistura de herbicidas de ação pré-emergente, visando-se o controle químico de plantas daninhas de folhas largas e estreitas.

Uma vez instaladas, as áreas experimentais foram sistematicamente monitoradas por meio de visitas para a coleta de dados. $\mathrm{Na}$ medida em que forem necessários, foram adotados os tratos culturais e o controle fitossanitário 
recomendados para a condução da cultura da soja.

Identificada a maturação de campo e realizadas as últimas coletas de dados, foi providenciada a colheita da área útil de cada parcela, por meio de colhedora automotriz de parcelas com regulagem da velocidade do cilindro batedor para 720 rotações por minuto. As sementes parcialmente limpas foram acondicionadas em sacaria de aniagem e identificadas de acordo com suas respectivas parcelas e tratamentos. Posteriormente, foram limpas e encaminhadas ao laboratório para determinação da produtividade.

As características avaliadas foram: a) $\mathrm{pH}$ das soluções de Lactofen e de micronutrientes: com a finalidade de verificar a alteração dos valores do $\mathrm{pH}$ das soluções de herbicida e de micronutrientes em relação a água, as soluções, depois de homogeneizadas, tiveram seus $\mathrm{pHs}$ lidos em pH-metro de bancada Tec-2, da Tecnal, do Laboratório de Fisiologia Pós-Colheita do Departamento de Ciências Biológicas da USP/ESALQ; b) avaliação da fitotoxicidade causada pelo herbicida Lactofen e produtividade agrícola: a intensidade de fitotoxicidade, proporção de área foliar injuriada por parcela, foi avaliada por meio de notas, utilizando-se a escala de valores, proposta pela European Weed Research Council (1964); c) produtividade de grãos.

Os efeitos estatisticamente significativos pelo teste $\mathrm{F}$ aplicado à análise de variância foram analisados pelo teste de Tukey para comparação das médias.

\section{RESULTADOS E DISCUSSÃO}

Os valores observados para o $\mathrm{pH}$ das soluções de Lactofen, cobalto e molibdênio foram obtidos a partir de leitura única em pH-metro, de amostras retiradas das soluções que restaram nos recipientes plásticos, após as pulverizações nas folhas de soja. Como não foram feitas repetições sistemáticas, tais valores não foram submetidos à análise de variância.

$\mathrm{Na}$ tabela 1 são apresentados os valores observados para o $\mathrm{pH}$ das soluções contendo apenas Lactofen, Co e Mo e para as soluções contendo misturas destes produtos.

Um aspecto que desperta a atenção é a acentuada redução dos valores de $\mathrm{pH}$ das águas em ambos os anos agrícolas, à medida que estas receberam Lactofen, Co, Mo, a mistura de $\mathrm{Co}+\mathrm{Mo}$ e as diferentes misturas entre estes produtos (Tabela 1).

Neste caso, pode-se inferir que o herbicida Lactofen em mistura com a água, potencializa a ação redutora do $\mathrm{pH}$ da solução ou emulsão herbicida, dispensando a utilização de outras substâncias redutoras de $\mathrm{pH}$, normalmente adicionadas em tanques de pulverização agrícola, como por exemplo, o ácido fosfórico. Além disso, isoladamente ou em mistura com os sais de molibdênio e de cobalto, o herbicida Lactofen reduz mais intensamente o pH da solução, do que os sais desses micronutrientes.

No planejamento desta pesquisa decidiuse pela aplicação da dose máxima do ingrediente ativo do herbicida Lactofen recomendada no Brasil (180 g i.a. ha ${ }^{-1}$ ), para, propositadamente, expressar o máximo de fitotoxicidade nas folhas do cultivar Conquista, de maneira a possibilitar a avaliação de possível amenização desses sintomas, por meio da aplicação simultânea ou não, de soluções contendo os micronutrientes cobalto e molibdênio.

Forns \& Devani (1999) descreveram os seguintes sintomas relacionados à fitotoxicidade de Lactofen aplicado em soja: manchas de coloração esbranquiçada e de aspecto brilhante ocorrendo dois a três dias após a aplicação, evoluindo, em alguns casos, aos sete dias após a pulverização, para manchas necróticas sobre as lâminas foliares, seguindo-se a queda de algumas folhas.

Os sintomas descritos por Forns \& Devani (1999) também foram observados 
nas folhas da cv. Conquista em todos os anos e locais de experimentação. Nas primeiras 24 horas após a pulverização do Lactofen, além de esbranquiçadas, as manchas se apresentaram prateadas e brilhantes. A partir do segundo dia após a pulverização, os sintomas se intensificaram, evoluindo para a descoloração (necrosamento) e encarquilhamento das folhas superiores e queima do ápice da haste principal (trifólios ainda fechados). Entretanto, não houve morte da gema apical vegetativa, pois os sintomas de fitotoxicidade desapareceram gradativamente com o desenvolvimento das plantas, por meio da emissão e expansão de folhas novas.

Souza et al. (2002) trabalhando com a aplicação de diferentes doses do herbicida Lactofen na cultura da soja, observaram que a ocorrência de fitotoxicidade provocada pelo Lactofen isolado, ou seja, sem combinação com outro herbicida, atingiu valores intermediários da escala EWRC no terceiro dia após a aplicação, ocorrendo necrose e deformação de folhas e brotos para as maiores doses (equivalentes às recomendações comerciais), sendo que, para as doses menores $(50$ e $25 \%$ da dose comercial) os sintomas ainda apresentavamse visíveis com forte descoloração e deformação, sem contudo apresentar necrose. Segundo os autores, com o desenvolvimento da cultura estes sintomas se tornaram menos intensos até o décimo dia após a aplicação, e a partir do vigésimo dia, desapareceram completamente.

Quanto à seletividade, Ferreira et al. (1998) verificaram acentuados sintomas de intoxicação nas plantas de soja causados pelo Lactofen, já no primeiro dia após as aplicações, sendo que estes sintomas praticamente desapareceram aos 15 dias após as aplicações, devido a emissão de novas folhas, isentas de sintomas de intoxicação.

Também, Damião Filho et al. (1992) relataram que o Lactofen ocasionou expressivas alterações morfológicas internas e externas das folhas, nos locais onde foi depositado, e que a maior dose $(0,36 \mathrm{~kg}$ i.a. $\mathrm{ha}^{-1}$ ) acentua os efeitos do produto sobre as plantas, sendo que as cultivares de soja apresentam diferentes graus de sensibilidade ao produto. Ruedell (1987) observou necrose generalizada nas folhas de soja e crescimento desigual entre as nervuras e o limbo foliar, resultando num aspecto de folhas encarquilhadas. Resultados semelhantes de intoxicação foram observados por Gazziero \& Neumaier (1985) em estudos de sobreposição de faixas de aplicação.

Por ocasião do estádio $\mathrm{V}_{5}$, a planta de soja se apresenta com um par de folhas unifolioladas totalmente expandidas, os três primeiros trifólios $\left(\mathrm{V}_{2}, \mathrm{~V}_{3}\right.$ e $\left.\mathrm{V}_{4}\right)$, também, bem expandidos, o quarto trifólio $\left(\mathrm{V}_{5}\right)$ entre 40 e $60 \%$ de sua expansão total e o quinto trifólio recém aberto. Acima deste, encontrase a extremidade apical da haste principal com trifólios totalmente fechados.

No momento da pulverização foliar de Lactofen sobre as plantas de soja no estádio fenológico $\mathrm{V}_{5}$, o ápice vegetativo da planta e os trifólios superiores $\left(\mathrm{V}_{3}, \mathrm{~V}_{4}\right.$ e $\left.\mathrm{V}_{5}\right)$, são os mais atingidos pelas gotas pulverizadas.Com o desenvolvimento fenológico da soja, a haste principal continua o seu crescimento em altura, emitindo, sucessivamente, novos trifólios. Ramificando-se a haste principal, incrementa-se a área foliar da cultura, de maneira que, transcorridos 15 a 20 dias após a aplicação do Lactofen, herbicida não sistêmico, não mais se observam sintomas de fitotoxicidade.

Os valores médios, para os dois anos de experimentação, correspondentes às notas de fitotoxicidade causada pela aplicação do herbicida Lactofen na soja, cv. Conquista, são apresentados na tabela 2 .

Independentemente do ano de experimentação, sempre se observaram as maiores intensidades de fitotoxicidade foliar da soja para os tratamentos envolvendo a 
presença do herbicida Lactofen (T3, T5, T6, T7, T9 e T11).

\section{CONCLUSÕES}

1. Isoladamente, ou em mistura com sais de cobalto e de molibdênio, o herbicida Lactofen, quando emulsionado em água, potencializa a redução do $\mathrm{pH}$ da solução.

2. Sais de cobalto e de molibdênio quando dissolvidos em água podem atuar como substâncias redutoras do $\mathrm{pH}$ da solução fertilizante.

3. A aplicação foliar do herbicida Lactofen no estádio fenológico $\mathrm{V}_{5}$ da cultura da soja causa fitotoxicidade às folhas, em grau variável de leve a médio. Esta fitotoxicidade, que com o desenvolvimento fenológico da soja, ou seja, crescimento da planta e emissão de novos trifólios, 15 a 20 dias após a aplicação foliar do Lactofen, não são mais observáveis.

\section{AGRADECIMENTOS}

Ao $\mathrm{CNPq}$ pela bolsa de doutorado e taxa de bancada concedidas à primeira autora.

\section{REFERÊNCIAS BIBLIOGRÁFICAS}

ALMEIDA, F.S.; RODRIGUES, B.N. 1988. Guia de herbicidas: contribuição para o uso adequado de plantio direto e convencional. 2 ed. Londrina, IAPAR, 503p.

DAMIÃO FILHO, C.F.; CORSO, G.M.; ANDRADE, V.M.M. 1992. Efeitos do herbicida lactofen sobre três cultivares de soja. Planta Daninha, v.10, p.1724 ..

EWRC-European Weed Research Council. 1964.Report of the $3^{\text {rd }}$ and $4^{\text {th }}$ meetings of EWRC. Committee of methods in weed research. Weed Research, Oxford, v.4, n.1, p.88.
FERREIRA, M.C.; MACHADO-NETO, J.G.; MATUO, T.1998.. Redução da dose e do volume de calda nas aplicações noturnas de herbicidas em pós-emergência na cultura de soja. Planta Daninha, v.16, n.1, p.25-36.

FORNS, A.C.; DEVANI, M. 1999.Manejo de atacos (Amaranthus quitensis) resistentes en el cultivo de soja. EEAOC - Avance Agroindustrial, p.35-37.

GAZZIERO, D.L.P.; NEUMAIER, N. 1985. Sintomas e diagnose de fitotoxicidade de herbicidas na cultura da soja. Londrina, EMBRAPA/CNPSo. 56p. (Documento, 13).

KAPUSTA, S.; JACKSON, L.A.; MASON, D.S. 1986.Yield response of weedfree soybeans (Glycine max) to injury from postemergence broadleaf herbicides. Weed Science, n.34, p.304-307.

MALAVOLTA, E. 1980. Elementos de nutrição mineral de plantas. São Paulo, Ed. Agronômica Ceres. 253p.

MARSCHNER, H. 1990. Mineral nutrition of higher plants. London: Academic Press, 674p.

RUEDELL, J. 1987. Culturas de verão: avaliação da eficiência e seletividade de herbicidas pós-emergentes na cultura da soja para o controle de dicotiledôneas. Cruz Alta: FECOTRIGO, 237p. (Resultados de Pesquisa - 1986/87)

SOUZA, R.T.; CONSTANTIN, J.;VELINI, E.D.; MONTORIO, G.A.; MACIEL, C.D.G. 2002.Seletividade de combinações de herbicidas latifolicidas com Lactofen para a cultura da soja. Scientia Agrícola, v.59, n.1, p.99-106, jan/mar..

TAYLOR, F.R. 1985.Today's herbicide: 
Cobra postemergence herbicide shows promise for procedures and PPG. Weed Today, n.16, p.3.

VELINE, E.D.; FREDERICO, L.A.; MORELLI, J.L.; MARUBAYASHI, O.M. 1992.Avaliação dos efeitos do herbicida clomazone, aplicado em pósemergência inicial, sobre o crescimento e produtividade de soqueira de canade-açucar (Saccharum officinarum cv.
SP 71-1406). STAB Açúcar, Álcool e Subprodutos, v.10, p.13-16.

WARREN, G.F.; HESS, F.D. Diphenylethers and oxadiazon. In: PURDUE UNIVERSITY. Herbicide action course. West Lafayette, Indiana, 1990. p.97-111.

WICHERT, R.A.; TALBERT, R.E. Soybean [Glycine $\max$ (L.)] response to Lactofen. Weed Science, v.41, p.2327,1993

Tabela 1. Valores de $\mathrm{pH}$ observados para a água utilizada no preparo das soluções, para as soluções individuais de Lactofen, cobalto e molibdênio, e para as soluções contendo misturas destas fontes em dois anos.

\begin{tabular}{ccc}
\hline Tratamentos & $\begin{array}{c}\mathbf{2 0 0 4} \\
\mathbf{p H}\end{array}$ & $\begin{array}{c}\mathbf{2 0 0 6} \\
\mathbf{p H}\end{array}$ \\
\hline Água & 5,98 & 5,74 \\
Co & 5,66 & 4,51 \\
Mo & 5,79 & 4,86 \\
Co + Mo & 5,34 & 4,66 \\
Lactofen & 5,58 & 4,41 \\
Co + Lactofen & 5,23 & 4,48 \\
Mo + Lactofen & 5,54 & 4,83 \\
$($ Co + Mo) + Lactofen & 5,09 & 4,68 \\
\hline
\end{tabular}


Tabela 2. Evolução da fitotoxicidade (notas EWRC) em plantas de soja, cv. Conquista, causada pela aplicação foliar do herbicida Lactofen em dois anos.

\begin{tabular}{|c|c|c|c|}
\hline \multirow{2}{*}{ Tratamentos $^{1}$} & \multicolumn{3}{|c|}{ Fitotoxicidade (2003/04 e 2005/06) } \\
\hline & $3 \mathbf{D A A}^{2}$ & $7 \mathbf{D A A}^{3}$ & 10 DAA \\
\hline T1 & $1,0 \quad \mathrm{c}$ & $1,0 \quad \mathrm{c}$ & $1,0 \quad \mathrm{c}$ \\
\hline $\mathbf{T} 2$ & $1,0 \quad \mathrm{c}$ & $1,0 \quad \mathrm{c}$ & $1,0 \quad \mathrm{c}$ \\
\hline $\mathbf{T 3}$ & $2,8 \mathrm{~b}$ & $3,0 \mathrm{~b}$ & $2,0 \mathrm{~b}$ \\
\hline $\mathbf{T 4}$ & $1,0 \quad \mathrm{c}$ & $1,0 \quad \mathrm{c}$ & $1,0 \quad \mathrm{c}$ \\
\hline $\mathbf{T 5}$ & $3,0 \mathrm{ab}$ & $3,0 \mathrm{ab}$ & $2,3 \mathrm{ab}$ \\
\hline T6 & $3,5 \mathrm{a}$ & $2,8 \mathrm{~b}$ & $2,0 \mathrm{~b}$ \\
\hline $\mathbf{T 7}$ & $1,0 \quad \mathrm{c}$ & $3,8 \mathrm{a}$ & $2,8 \mathrm{a}$ \\
\hline T8 & $1,0 \quad \mathrm{c}$ & $1,0 \quad \mathrm{c}$ & $1,0 \quad \mathrm{c}$ \\
\hline T9 & $3,0 \mathrm{ab}$ & $2,8 \mathrm{~b}$ & $2,0 \mathrm{~b}$ \\
\hline T10 & $1,0 \quad \mathrm{c}$ & $1,0 \quad \mathrm{c}$ & $1,0 \quad \mathrm{c}$ \\
\hline T11 & $3,3 \mathrm{ab}$ & $3,0 \mathrm{~b}$ & $2,0 \mathrm{~b}$ \\
\hline $\mathrm{CV} \%$ & 13,36 & 13,64 & 12,81 \\
\hline
\end{tabular}

${ }^{\top} \mathrm{T} 1$ = Controle; $\mathrm{T} 2$ = Tratamento de sementes com Co e Mo; T3 = Tratamento de sementes com Co e Mo + aplicação de herbicida em $\mathrm{V}_{5}$; T4 = Aplicação foliar de Co e Mo em $\mathrm{V}_{5}$; T5 = Aplicação foliar de Co e Mo + herbicida em $\mathrm{V}_{5}$; $\mathrm{T} 6=$ Aplicação de herbicida em $\mathrm{V}_{5}+$ foliar de Co e Mo 3 a 5 dias após; T7 = Aplicação foliar de Co e Mo em $V_{5}+$ aplicação de herbicida 3 a 5 dias após; $\mathrm{T} 8=$ Aplicação foliar de Co em $\mathrm{V}_{5}$; T9 = Aplicação foliar de Co + herbicida em $\mathrm{V}_{5}$; T10 = Aplicação foliar de Mo em $\mathrm{V}_{5}$; T11 = Aplicação foliar de Mo + herbicida em $\mathrm{V}_{5}$.

${ }^{2} \mathrm{DAA}=$ Dias Após Aplicação em $\mathrm{V}_{5}$.

${ }^{3}$ As aplicações complementares de Co e Mo (T6) e do herbicida Lactofen (T7) ocorreram cinco dias após o estádio $\mathrm{V}_{5}$ do cv. Conquista, e as respectivas fitotoxicidades foram avaliadas 10 DAA.

Médias seguidas da mesma letra minúscula na coluna não diferem entre si, pelo teste de Tukey ( $p>0,05)$. 